\title{
StALKing Histiocytosis: ALK-Positive Histiocytosis Identified through Peripheral Blood Smear
}

\author{
Jeffrey R. Andolina \\ Department of Pediatrics, Golisano Children's Hospital, University of Rochester Medical Center, Rochester, NY, USA
}

The histiocytoses are a rare, heterogeneous group of disorders defined by proliferation of histiocytes in numerous organs, including the skin, bone marrow, liver, bone, and/or other organs [1]. Classification systems have evolved over time, and there are now five groups, defined by cell of origin, molecular mutations, and clinical behavior [1]. Langerhans cell histiocytosis (LCH) is the most common disorder in this category, is confirmed with histologic expression of CD1a and CD207, and most commonly affects bone and skin. Non-LCH disorders, of which there are many, and of which may include overlapping pathologic or clinical features, include ErdheimChester disease, juvenile xanthogranuloma, Rosai-Dorfman syndrome, malignant histiocytoses, and hemophagocytic lymphohistiocytosis (HLH), among others [1]. Molecular features are increasingly recognized in the histiocytoses: BRAF mutations and MAPK pathway alterations are the most commonly identified mutations in this group of disorders [2]. However, the significant variability in presentation, histology, molecular findings, and clinical behavior make these disorders challenging for the clinician.

The article published by Swain et al. [3] report upon a newborn diagnosed with ALK-positive histiocytosis. The newborn presented with severe thrombocytopenia, intermittent anemia and neutropenia, and hepatospleno-

$\begin{aligned} & \text { karger@karger.com } \\ & \text { www.karger.com/aha }\end{aligned}$
Karger $\%$

megaly. Importantly, clinicians noted the presence of histiocytes on the peripheral blood smear, an uncommon, and novel finding. The patient also had increased histiocytes and evidence of hemophagocytosis on bone marrow biopsy. The histiocytes stained positive for ALK (anaplastic lymphoma kinase), though genetic ALK mutation/translocation could not be identified by FISH (fluorescence in situ hybridization) or RT-PCR (reverse transcription polymerase chain reaction). Despite being ill, the patient did not receive any therapy directed at histiocytosis, and she improved over time with observation alone, highlighting the unpredictable behavior of this condition.

This case report is unique in that the diagnosis was suspected and identified by peripheral blood smear review. In addition, this adds to the literature on ALK-positive histiocytosis, which is clearly a distinct entity. Chang et al. [4] nicely summarized the largest reported series of 10 patients with ALK-positive histiocytosis. Seven of the reported patients were young infants or toddlers, while 3 patients were adults. The ALK gene fusion was confirmed in 8 of 10 patients (KIF5B-ALK in 5; COL1A2 in 1; TPM3$A L K$ in 1; ALK translocation by FISH partner unknown in 1) [4]. Therapy included chemotherapy in 5, ALK inhibitor in 1 , surgery in 2 , and observation in 1 . This series of patients generally had good outcomes: 9 of 10 are alive. 
The authors conclude that ALK expression should be tested in unusual histiocytic syndromes. The current case report would fit similarly, and suggests that observation remains a reasonable approach.

Translocations or mutations involving the ALK gene may result in ALK fusion genes which code abnormal ALK proteins (transmembrane tyrosine kinase receptors), which are presumed to be oncogenic and found in multiple cancers [5]. The ALK gene is found on chromosome $2 \mathrm{p} 23$, and derives its name from the characteristic $\mathrm{t}(2 ; 5)(\mathrm{p} 23 ; \mathrm{q} 35)(A L K-N P M)$ translocation found in anaplastic large cell lymphoma [5]. ALK translocations are most commonly associated with non-small cell lung cancer (NSCLC) in adults $[5,6]$, and ALK mutations are seen in pediatric neuroblastoma tumors [6] as well as in germline mutations in familial neuroblastoma [7]. In addition to the above cancers, ALK translocations have been identified in inflammatory myofibroblastic tumor, epithelioid fibrous histiocytoma, and numerous carcinomas [4]. ALK-positive histiocytosis, most commonly harboring $K I F 5 B-A L K$, is another entity defined by this gene [4].

Identifying targetable mutations has led to successful therapy with ALK inhibitors for many of the above malignancies. Crizotinib is the most commonly used ALK inhibitor, is generally well tolerated, and is approved to treat NSCLC with ALK translocation [5]. Crizotinib is also used to treat other malignancies with ALK translocations, and is currently under investigation to treat ALKmutated neuroblastoma [8]. In the ALK-positive histiocytosis case series by Chang et al. [4], 1 patient was treated with crizotonib, and the patient had a complete response. In addition, second and third generation ALK inhibitors have been developed and are under investiga- tion. ALK inhibitors should be considered as a potential therapy for ALK-positive histiocytosis.

Treatment of unusual histiocytoses remains difficult, as the clinical course of these disorders can be very difficult to predict, and varies from progression to death to spontaneous resolution over time. In the case report by Swain et al. [3], a conservative, observation-only approach was undertaken, and was successful. This adds to the literature to consider observation for these disorders, when able.

The histiocytoses remain a challenging group of disorders, both in terms accurate classification, diagnosis, and treatment. ALK-positive histiocytosis has emerged as a rare, but genetically-distinct entity, as described in this case report. Peripheral blood smear evaluation, ALK immunohistochemistry, and cytogenetic evaluation for ALK translocations are important steps to identify this rare condition, and ALK inhibitors have become a promising therapeutic option.

\section{Conflict of Interest Statement}

J.A. has no conflicts of interest to disclose.

\section{Funding Sources}

No funding was received.

\section{Author Contributions}

J.A. wrote the commentary.

\section{References}

1 Emile JF, Abla O, Fraitag S, Horne A, Haroche J, Donadieu J, et al.; Histiocyte Society. Revised classification of histiocytoses and neoplasms of the macrophage-dendritic cell lineages. Blood. 2016 Jun;127(22):2672-81.

2 Papo M, Cohen-Aubart F, Trefond L, Bauvois A, Amoura Z, Emile JF, et al. Systemic Histiocytosis (Langerhans Cell Histiocytosis, Erdheim-Chester Disease, Destombes-RosaiDorfman Disease): from Oncogenic Mutations to Inflammatory Disorders. Curr Oncol Rep. 2019 May;21(7):62.

3 Swain FW, Barbaro P. ALK-positive histiocytosis with peripheral blood histiocytes: a case report. Acta Haematol. DOI: 10.1159/508524.
4 Chang KT, Tay AZ, Kuick CH, Chen H, Algar E, Taubenheim N, et al. ALK-positive histiocytosis: an expanded clinicopathologic spectrum and frequent presence of KIF5B-ALK fusion. Mod Pathol. 2019 May;32(5):598608.

5 Du X, Shao Y, Qin HF, Tai YH, Gao HJ. ALKrearrangement in non-small-cell lung cancer (NSCLC). Thorac Cancer. 2018 Apr;9(4): 423-30.
6 Bresler SC, Weiser DA, Huwe PJ, Park JH, Krytska K, Ryles H, et al. ALK mutations confer differential oncogenic activation and sensitivity to ALK inhibition therapy in neuroblastoma. Cancer Cell. 2014 Nov;26(5):68294.

7 Mossé YP, Laudenslager M, Longo L, Cole KA, Wood A, Attiyeh EF, et al. Identification of ALK as a major familial neuroblastoma predisposition gene. Nature. 2008 Oct; 455(7215):930-5.

8 Krytska K, Ryles HT, Sano R, Raman P, Infarinato NR, Hansel TD, et al. Crizotinib Synergizes with Chemotherapy in Preclinical Models of Neuroblastoma. Clin Cancer Res. 2016 Feb;22(4):948-60. 